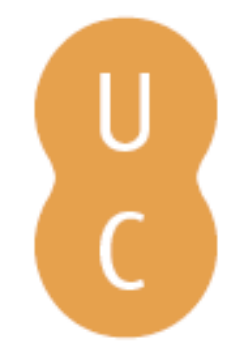

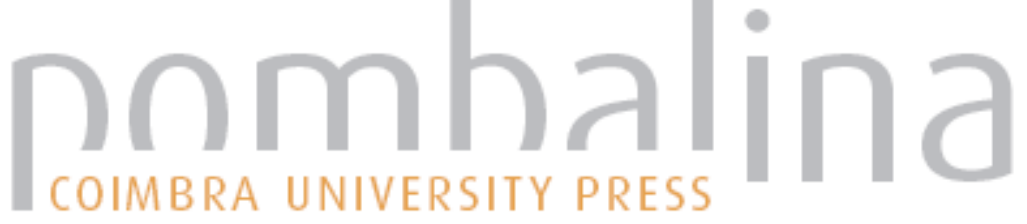

Oratoria y biografía: el retrato de Alcibíades en Lisias e Isócrates

Autor(es): $\quad$ Calvo Martínez, José Luís

Publicado por: Imprensa da Universidade de Coimbra

URL

persistente:

URI:http://hdl.handle.net/10316.2/32562

DOI:

DOI:http://dx.doi.org/10.14195/978-989-26-0442-8_3

Accessed : $\quad$ 26-Apr-2023 14:14:51

A navegação consulta e descarregamento dos títulos inseridos nas Bibliotecas Digitais UC Digitalis, UC Pombalina e UC Impactum, pressupõem a aceitação plena e sem reservas dos Termos e Condições de Uso destas Bibliotecas Digitais, disponíveis em https://digitalis.uc.pt/pt-pt/termos.

Conforme exposto nos referidos Termos e Condições de Uso, o descarregamento de títulos de acesso restrito requer uma licença válida de autorização devendo o utilizador aceder ao(s) documento(s) a partir de um endereço de IP da instituição detentora da supramencionada licença.

Ao utilizador é apenas permitido o descarregamento para uso pessoal, pelo que o emprego do(s) título(s) descarregado(s) para outro fim, designadamente comercial, carece de autorização do respetivo autor ou editor da obra.

Na medida em que todas as obras da UC Digitalis se encontram protegidas pelo Código do Direito de Autor e Direitos Conexos e demais legislação aplicável, toda a cópia, parcial ou total, deste documento, nos casos em que é legalmente admitida, deverá conter ou fazer-se acompanhar por este aviso. 
Aurelio Pérez Jiménez, Joșé Ribeiro Ferreira

e Maria do Céu Fialho

(COORdinadores)

\section{Adminiftri Principum.}

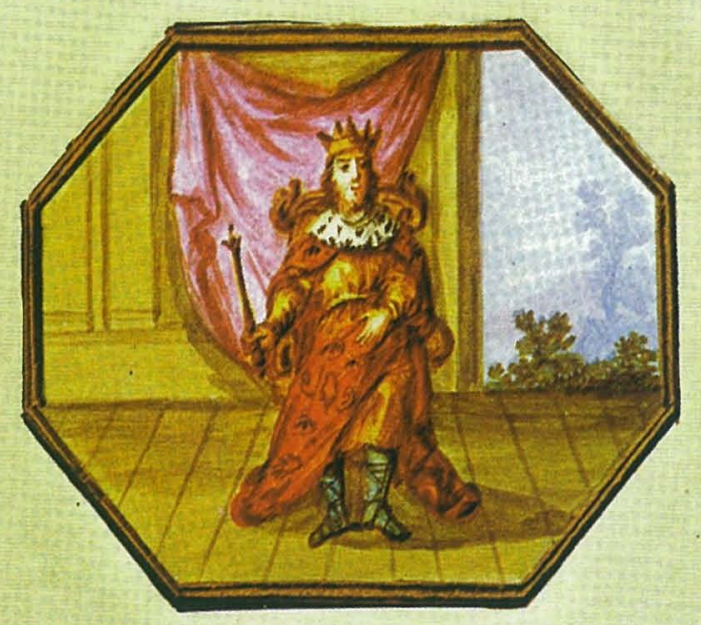

\section{EMBLEM A LIV.}

En tibi plura gerit, quàm lumina prabuit Argos Rex; Aures totidem, quin totidemó, manus. Hec opus Imperio, fidis fupplenda Minijtris, Regi bi funt aures: lumina clara, manus.

\section{- Retrato e a Biografia como estratégia de teorização política}

IMPRENSA DA UNIVERSIDADE DE COIMBRA

Universidad de MálaGa 
(Página deixada propositadamente em branco) 
Aurelio Pérez Jiménez

José RIBEIRo FERREIRA

Maria do Céu Fialho

O RETRATO LITERARIO E A BIOGRAFIA COMO ESTRATÉGIA

\section{DE}

TEORIZACCÃO POLITICA

IMPRENSA DA UNIVERSIDADE DE COIMBRA

UnIVERSIDAD DE MÁlaGa

2004 
Obra publicada com a colaboração de:

Centro de Estudos Clássicos e Humanísticos (Universidade de Coimbra)

International Plutarch Society

Primera edição, Junho de 2004

(c) IMPRENSA DA UnIVERSIDADE DE COIMBRA

(c) Área de Filología Griega. Universidad de Málaga

Coordenação editorial:

Imprensa da Universidade de Coimbra

Área de Filología Griega de la UMA

ISBN: 972-8704-25-9 (PORTUGAL)

ISBN: 84-608-0166-7 (ESPANHA)

Depósito Legal: MA-1420

Impresso em Espanha

Execução gráfica:

IMAGRAF IMPRESORES, S.A.

c/ Nabucco 14

29006 Málaga

Tfno. 952328597

Página de rosto:

"Dos Princepes Transùmptos verdadeiros": Francisco António Novaes Campos, Principe perfeito. Emblemas de D. Joâo de Solórzano. Edição fac-similada do manuscrito da Biblioteca Nacional do Rio de Janeiro oferecido ao Príncipe D. João em 1790 (Prefácio, introdução, comentário e índices por Maria Helena de Teves Costa Ureña Prieto), Instituto de Cultura e Língua Portuguesa, Lisboa, 1985, Emblema LIV, p. 114. 


\section{ORATORIA Y BIOGRAFÍA El Retrato de Alcibíades en Lisias e Isócrates}

José Luis Calvo Martinez

Universidad de Granada

No deja de ser llamativo que sea la Oratoria el género literario en que menos han pensado los tratadistas de la biografía griega a la hora de buscar en ella elementos que han podido contribuir al origen del género. Es tanto más llamativo cuanto que la Biografía, juntamente con la Historia, es un género de la prosa que se ocupa de los asuntos humanos - y la Oratoria, en mayor medida que la Historia, de los asuntos del individuo más que de los pueblos. Los tratamientos usuales sobre el género se remontan incluso hasta Hesíodo en la búsqueda de elementos que pudieran suponer un precedente para el mismo, pero, curiosamente, no suelen dar a la Oratoria la importancia que se merece.

Es cierto que un autor de la talla de Momigliano advierte a propósito de los Apomnemoneumata de Jenofonte que la intención de este autor al escribir la defensa de Sócrates responde a la frase enunciada por Lisias: «in the dokimasiai one is justified in giving an account of the whole life» ${ }^{1}$. Pero ello sucede, me atrevería yo a añadir, no sólo en las dokimasiai. Cualquier clase de proceso penal permite, e incluso induce, al acusado a dar cuenta, para defenderse, de su conducta intachable, su orgullo de ciudadano y sus prestaciones al Estado - lo cual desemboca necesariamente en una autobiografía. Por su parte, el acusador tiene que hacer exactamente lo contrario, lo que conduce, en este caso, a una biografía del acusado. Y, claro, si alguno de ellos es un personaje público, o pertenece a un grupo influyente

1 The Development of Greek Biography, Cambridge, Mass., 1971, p. 53.

A. Pérez Jiménez, J. Ribeiro Ferreira, Maria do Céu Fialho (edd), O retrato literário e a biografia como estratégia de teorização política, Coimbra-Málaga, 2004, pp. 37-48. 
formado por miembros relevantes en la vida política de Atenas, podemos afirmar que estamos ante una biografía en toda regla.

Si se examina, pues, desde esta perspectiva, es fácil observar que casi en cada discurso hay una pequeña biografía $\mathrm{o}$, al menos, un retrato. Al fin y al cabo el protagonista de un discurso siempre es un individuo que es acusado o defendido. Y, dada la ordenación procedimental jurídica del Estado ateniense, en que el fundamento mismo del ataque o la defensa son las "pruebas enteknoi", una buena parte del proceso, de cualquier proceso, se dedica a resaltar el carácter, el ethos, del acusado ó del defendido. Y esto se realiza, naturalmente, mediante la descripción de su trayectoria vital, positiva o negativa según lo exijan las circunstancias. En realidad, en el primer caso nos encontramos con una suerte de encomio; en el segundo, con la llamada diabole ${ }^{2}$; y no hay que olvidar que, dentro de la biografía, hay exactamente dos subclases: la encomiástica y la denigratoria.

Ahora bien, el que esta biografía sea una parte de otra pieza más amplia hace que sea sumaria y, en cuanto a la estructura, no necesariamente cronológica; de otro lado, el hecho de que esta parte, aunque esté inserta en la diegesis del discurso, tenga una finalidad esencialmente probatoria, hace que sea una descripción coherente del ethos más que una acumulación inorgánica de acciones y dichos. Por tanto, no hay necesidad de atribuir exclusivamente a la escuela peripatética el carácter ético, que es esencial en la biografía griega una vez que cristalizó como género. Ya vemos que se encuentra en la Oratoria, e igualmente podemos descubrirlo en la Historia, aunque en ésta su finalidad no sea necesariamente probatoria y por tanto esté menos condicionada a resaltar los rasgos del carácter de un individuo relevante.

No es mi intención teorizar aquí sobre la Oratoria como posible fuente donde pudieron beber, o, al menos, inspirarse los primeros autores de biografías, aunque parece inevitable pensar que así fuera. Pero sí quiero señalar que esta suposición no es imprudente, si consideramos los nexos que tienen una y otra. Pero, en fin, para concretar, admitamos que hay al menos dos rasgos definitorios que las relacionan: de un lado, la intencionalidad, ya señalada, de ensalzar o denigrar a un individuo. En realidad, ya el propio relato histórico nació como género y se desarrolló con la intención de justificar grandes acciones y exaltar a los grandes pueblos. La objetividad nunca fue un rasgo pertinente, y mucho menos una condición necesaria, del género histórico. La segunda nota que une biografía y retórica es su intento de resaltar el carácter (ethos) de un individuo a través de sus acciones y palabras. 
Mas no pretendo extenderme más sobre este asunto; mi propósito es aquí más modesto. Dentro del marco de este coloquio voy a referirme a los elementos biográficos, en sentido amplio, que se encuentran en la parte narrativa de los discursos (diegesis), aunque también puedan aparecer ocasionalmente en la demostración. Y luego, más concretamente, me detendré en uno de los personajes más importantes de los que aparecen en el Corpus Lysiacum. Dado que Lisias vivió su madurez vital e intelectual en años cruciales de la historia de Atenas (final de la guerra del Peloponeso, régimen oligárquico de los Treinta y restauración democrática), la galería de personajes que desfilan por sus discursos es amplia e importante: muchos de ellos eran sobradamente conocidos en Atenas, aunque para nosotros son simples nombres; otros, en cambio, han pasado a la historia como personajes decisivos: es el caso de Alcibíades, Terámenes y Nicias; o el personaje colectivo de los Treinta. Por otra parte, interesa señalar que el propio Lisias participó activamente en los hechos dentro de las filas del partido democrático, por lo que su actitud en general ha de ser necesariamente parcial y su bosquejo de los personajes implicados no puede ser objetivo en manera alguna. Por tanto, todo induce a sospechar que cualquier utilización que haga Lisias de los personajes públicos, está pensada desde la óptica del grupo democrático que sufrió los desmanes de los Treinta y combatió para expulsarlos y, al fin, restaurar la democracia. Es el grupo de los demócratas moderados, aunque intransigentes hacia cualquier tipo de veleidad para con los laconios - es decir, los demócratas que se agrupaban en torno a figuras como Trasíbulo o Ánito. Dado que la situación en esos años era de enfrentamiento civil y militar, y que en los años inmediatamente siguientes a ellos, como demuestra precisamente la obra de Lisias y otros oradores, se hizo una utilización partidista de figuras como las anteriormente nombradas, por entonces ya desaparecidas pero recordadas por los oyentes de Lisias, es de esperar que los testimonios que conservamos sean diferentes y hasta opuestos, al menos en su interpretación, de acuerdo con el posicionamiento político del hablante - ya sea el orador o su cliente. De manera que, si en el caso de un autor como Tucídides o Jenofonte la visión parcial se explica sencillamente en virtud de su propia ideología, o de sus filias y fobias personales, que son inevitables, en el de Lisias a menudo la parcialidad, que por otra parte no oculta el autor, a menudo viene exigida por el propio contexto agonal en que se inscribe su obra: el proceso forense.

Existen, por otra parte, grandes diferencias dentro de estos elementos biográficos que encontramos en un discurso: hay autobiografía, hay biografía más o menos encubierta y, muy a menudo, hay el simple retrato de un personaje que Lisias consigue con cuatro pinceladas mediante su reconocida maestría en el arte de la etope- 
ya. Para empezar, tenemos en el discurso XII una autobiografía del propio Lisias a decir verdad, la primera autobiografía que se escribió en Grecia consciente e intencionadamente. Es ciertamente breve y está inserta en un discurso de acusación, por lo que sólo se refiere a los hechos pertinentes. Pero es una biografía del personaje que está hablando, como demuestra su propia forma narrativa. Baste con aducir aquí el comienzo del párrafo 4: «Pericles persuadió a mi padre Céfalo para que se viniera a esta tierra. La habitó durante treinta años y nunca, ni nosotros ni él, suscitamos juicio contra nadie ni lo afrontamos. Antes bien, de tal manera vivimos bajo la democracia, que ni cometimos delito contra los demás ni lo sufrimos por parte de los otros. Cuando los Treinta, que eran perversos y sicofantas, se instalaron en el poder alegando que era preciso limpiar la ciudad de delincuentes y encaminar a los demás ciudadanos hacia la virtud»...; y así sigue el orador relatando los hechos fundamentales de su vida que afectan al proceso.

Esta autobiografía, claro está, se inscribe a su vez en un retrato de lo que podríamos llamar el personaje colectivo de los Treinta. Evidentemente la intención de Lisias no es contar la historia del régimen oligárquico, sino trazar un dibujo negativo del mismo: pues bien, su maestría en la diegesis o narratio consigue que, seleccionando a tres miembros de los Treinta tiranos (Melobio, Teognis y Pisón, además de Eratóstenes que es el acusado), y con varias pinceladas, nos quede la imagen indeleble de un grupo de individuos codiciosos, sin principios y criminales que ejemplifican adecuadamente la aseveración con que el orador los introduce en el relato: «cuando se instalaron los Treinta que eran perversos y sicofantas»... (cf. supra). La imagen de Pisón aceptando el soborno del orador y registrando los baúles en busca de las joyas, o la de Melobio arrancándole los pendientes a la mujer de Polemarco ${ }^{3}$, hace que pensemos en cualquier cosa menos en un grupo de aristócratas que pretendían restaurar la patrios politeia de Solón no sin antes limpiar la ciudad de malhechores ${ }^{4}$.

Pero, importante como es el retrato del grupo de los Treinta, aquí estamos hablando de biografía en un sentido muy amplio. Veamos, pues, el tratamiento más propiamente biográfico que realiza Lisias de una figura fundamental en la política de esos años: Alcibíades ${ }^{5}$. El caso de este personaje es especialmente revelador por-

3

4 5

\section{Cf. XII, $\S \S 8-20$.}

Tal era su pretensión en un principio, como confirman Aristóteles, Constitución de los Atenienses 34.2 y ss., y Jenofonte, Helénicas, II 3.2 (ver también Platón, Carta VII 324d).

Después de la ya clásica biografía del personaje por J. Hatzfeld (Alcibiade: étude sur l'histoire de Athènes à la fin du V siècle, Paris, 1951) han tardado en aparecer más trabajos sobre el personaje. Últimamente, en fin, se han publicado varios dignos de mención entre los que destaco, por supuesto, el de J. de Romilly (Alcibiade ou les dangers 
que su figura, aparte de los testimonios de Tucídides y Jenofonte, está delineada en sentidos opuestos nada menos que por tres oradores: Lisias y Andócides por un lado, e Isócrates por otro. Insisto en que la figura de Alcibíades es importante porque después de la guerra del Peloponeso y de la guerra civil, y restaurada la democracia, es sabido que se produjo en Atenas una oleada de procesos que en definitiva trataban de deslindar responsabilidades por el terrible fracaso. Naturalmente los procesos no podían ser por delitos directamente relacionados con los hechos de los años 403-2 porque lo prohibían expresamente, con pocas excepciones, los Pactos del Pireo ${ }^{6}$. Por otra parte, los actores directos y principales del drama habían muerto. Por eso se aprovechaban indirectamente los litigios de quienes tenían vínculos con aquellos para inculparlos - o exculparlos - no sólo a ellos, sino, eventualmente, a todo su grupo político. Hubo sin duda muchos procesos de esta índole, pero hay dos personajes que sirvieron paradigmáticamente para canalizar el odio de sus adversarios: Sócrates fue, muy probablemente, el chivo expiatorio, el pharmakos, de Critias y los Treinta; y el hijo de Alcibíades sirvió más de una vez como excusa para atacar o defender a su padre, y, con él, la política belicista del grupo democrático dominante. Éste personaje, todavía veinte años después de su muerte, tenía numerosos tanto detractores como defensores: su figura se había convertido en un símbolo y se había agigantado considerablemente, como es natural en un hombre en el que todo era desmesurado. No hay que olvidar su papel en la expedición de Sicilia y por tanto en la derrota final de Atenas; o sus relaciones con la corte persa, ya al final de su vida, que lo convirtieron casi en un sátrapa oriental.

Para entrar ya en el asunto que nos concierne, diré que son tres los discursos que contienen elementos biográficos de Alcibíades: el discurso número IV, atribuido a Andócides, el XIV del Corpus Lysiacum (Contra Alcibíades I) y el XVI de Isócrates (el De bigis). Prescindiremos del que se atribuye a Andócides, en gracia a la brevedad de la exposición y por el hecho de que es independiente de los otros dos, aunque forma parte, junto con el de Lisias, de la corriente de escritos que tratan de demoler la figura de Alcibíades como personaje público. En cambio, el Contra Alcibíades $I$ de Lisias ${ }^{7}$ está íntimamente relacionado con el De bigis de Isócrates,

de l'ambition, Paris, 1993), los de W. Ellis (Alcibiades, London, 1989) y S. Forde (The ambition to rule: Alcibiades and the Politics of Imperialism in Thucydides, Ithaca, 1989), y el muy reciente de D. Gribble, Alcibiades and Athens: a study in literary Presentation, Oxford, 1999.

6 Cf. Aristóteles, Constitución de los Atenienses 39.6.

7 En realidad, los editores suelen asignar al XIV el título Contra Alcibiadem Prior y al XV Contra Alcibiadem Altera. Los estudiosos de Lisias consideran ambos discursos como 
escrito hacía el año 396 y que aprovechaba igualmente un proceso contra Alcibíades junior para, en este caso, defender y exaltar la figura del padre.

Se impone, por tanto, revisar previamente el de Isócrates. El planteamiento del litigio, cuya realidad histórica se ha puesto en duda como en el caso de Andócides, se sustenta en uno de los actos de hybris bien conocidos de la vida de Alcibíades. Para competir en Olimpia en la ocasión en que venció brillantemente, según la versión de los partidarios de Alcibíades, éste encargó a un tal Diomedes que adquiriera para él un carro excelente que había en Argos; según la parte contraria, el carro era propiedad de Diomedes a quien se le había pedido prestado y a quien nunca se lo devolvió. Esto provocó un litigio, iniciado el 408 e interrumpido por la guerra, que se reanudó una vez muerto Alcibíades y, probablemente, Diomedes. Porque los litigantes en el discurso de Isócrates son el hijo de Alcibíades como acusado y un tal Tisias como acusador. Pero, en realidad, lo mismo que en el Ps. Andócides, el litigio es lo menos importante; la verdadera finalidad del discurso es realizar un "encomio" de Alcibíades - una biografía positiva que ocupa 37 párrafos en un discurso de 50 - es decir, el $74 \%$ de su extensión. La justificación de este extenso epainos es el primer argumento que utiliza Alcibíades junior en su favor: exponer la vida de su padre, dice, es para él necesario porque de hecho la acusación va dirigida contra su padre. Seguramente el discurso de acusación contenía una diabole completa de Alcibíades aprovechando, sin duda, los topoi que aparecen en el Ps. Andócides y que se van a repetir en Lisias ${ }^{8}$.

Así que a partir del $\S 5$ comienza la biografía: la estructura formal está articulada sobre dos parámetros, el cronológico y la contraposición, de carácter retórico, entre lo público y lo privado - aunque de hecho Isócrates no entra en lo privado sensu stricto, sino más bien en lo familiar, y especialmente en los méritos políticos de su familia. En su conjunto la biografía consta de tres partes: una primera con los hechos políticos más relevantes del personaje, una segunda sobre su vida familiar (no desligada, repito, de lo público) y una tercera en que se justifica su actitud, más que sus actos, como hombre público. Desde el comienzo hasta el $\S 22$ se refiere a su vida pública y se mezclan casi a partes iguales la justificación o negación de sus actos reprobables $-\mathrm{o}$ al menos generalmente reprobados - con la

synegoriai (es decir, deuterología y tritología) de un proceso de "alistamiento ilegal" (astrateía), por más que los acusadores mezclan varios tipos de proceso militar (deilía y lipotaxíou o deserción, sobre todo). De los dos discursos, el que aquí nos interesa es el primero, al que designamos como Contra Alcibiades I. Cf. L. Gil, Lisias. Discursos, Madrid, $1986^{2}$, vol. II, pp. 69 ss.

8 Cf. M. Turchi, «Motivi della polemica su Alcibiade negli oratori attici», Par. Pas. 39 (1984) 105-119. 
exaltación de sus acciones y su actitud positiva hacia Atenas. Ello con razones a veces creíbles y otras con la manipulación cronológica de los hechos o mediante la mentira pura y simple. Por ejemplo, $\S 5-8$ contienen un relato deliberadamente confuso de los hechos relativos a la mutilación del Hermes y la mofa de los Misterios: según Tucídides ${ }^{9}$, Alcibíades fue elegido estratego para la expedición de Sicilia en una primera asamblea; y en una segunda se trató el tema de la profanación de los Hermes y los Misterios sin que se llegara a ningún acuerdo. Isócrates cambia la secuencia: primero se habría tratado el tema de los Hermes y luego Alcibíades fue elegido estratego, con lo que da entender que en un principio no sólo se le exculpó, sino que se le premió con el generalato. En el capítulo de los actos de traición hacia Atenas, el orador acude a la justificación y a la mentira - a veces a las dos juntas: de una lado, asegura que primero se dirigió a Argos y después, ante el acoso de Atenas, tuvo que refugiarse en Laconia ${ }^{10}$, mientras que, según Tucídides, se dirigió directamente allí ${ }^{11}$ precisamente porque sus "xenoi" de Argos eran sospechosos de conspirar contra la democracia. También afirma Isócrates que nunca aconsejó la ocupación de Decelia por los espartanos, y, sobre todo que, si atacó Atenas, no otra cosa hicieron los demócratas en la guerra civil ocupando el Pireo, talando el país y asaltando los muros - un argumento muy débil, como se ve, que luego rebatirá Lisias. En fin, entre sus favores a Atenas, realizados antes de su primer exilio, se alega en primer lugar que nunca colaboró con los oligarcas el 411 (los Cuatrocientos); que consiguió personalmente separar de Esparta a Estados importantes del Peloponeso como Argos, Mantinea y Élide; que tampoco colaboró con los Treinta - antes bien, fue expulsado por ellos - y que durante el exilio ganó muchas victorias y separó a Tisafernes de los espartanos. Todo ello es cierto, pero luego añade que devolvió el poder al pueblo - lo cual es falso; y que acabó con la defección de $\operatorname{los}_{\text {aliados }}{ }^{12}$, lo que, además de falso, es cínico porque debió hacerlo y no lo hizo - especialmente con los quiotas.

Invirtiendo el orden normal de la biografía, pasa ahora Isócrates a hablarnos de la familia y muy poco de su vida privada, quizá porque era de sobra conocida y poco

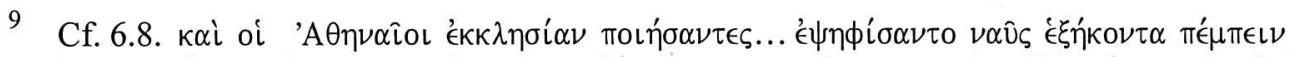

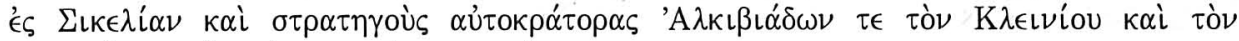

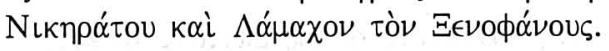

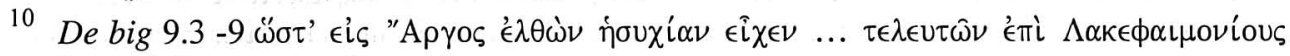

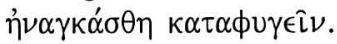

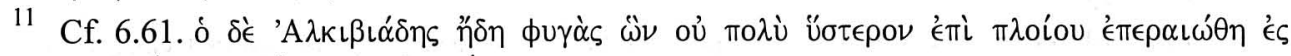

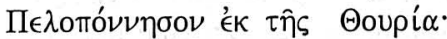

12 Cf. ibid. $\S 18-21$. 
edificante. La intención de Isócrates es demostrar que la arete de Alcibíades procede de la familia, que es hereditaria - idea eminentemente aristocrática. Para ello utiliza el mismo procedimiento de exagerar y mezclar lo verdadero con lo falso. Así, comienza diciendo que sus antepasados, los Alcmeónidas, aunque eran familia del tirano Pisístrato, no participaron de la tiranía sino que, más bien, fueron exilados por el tirano. A sus abuelos Alcibíades y Clístenes no sólo les atribuye el establecimiento de la democracia, sino el derrocamiento de la tiranía. Como confirmación del carácter hereditario, afirma Isócrates que Alcibíades recibió su eunoia hacia el pueblo como herencia de su padre, que murió combatiendo en Coronea, y de su tutor Pericles, que era tenido por todos como sophronestatos, dikaiotatos y sophotatos. En realidad, le está atribuyendo las cuatro virtudes cardinales: la andreia de su padre y la sophrosyne, dikaiosyne y phronesis de Pericles ${ }^{13}$. En todo caso, esta arete heredada justifica sus proezas bélicas (hace referencia, por ejemplo, a la batalla de Potidea donde Alcibíades fue premiado por su andreia con una corona y una armadura) y sus proezas atléticas en Olimpia donde - se atreve a afirmar cínicamente Isócrates - se puso de manifiesto que los bienes públicos eran inferiores a los privados de Alcibíades $^{14}$. Sus adversarios decían, por el contrario, que el carro con el que ganó no era suyo y los vasos sagrados con los que realizó una fiesta paralela a la oficial eran de los teoros atenienses. En fin, su casamiento con la hija de Calias, el hombre más rico de Atenas, fue un premio a su valor (aristeion) ${ }^{15}$. Con la alusión a su victoria en Olimpia termina la relación de datos propiamente biográficos.

La tercera parte de este bios encomiástico constituye una exaltación del personaje en la que se produce, en fin, una identificación de Alcibíades con la polis que se podría resumir en la siguiente frase: "cuando Atenas era feliz y tenía éxito, Alcibíades era feliz y tenía éxito; y cuando fracasaba Atenas, fracasaba Alcibíades"16. Pero, claro, la polis es el cuerpo de ciudadanos demócratas: porque lo que en definitiva se busca es demostrar la eunoia "antigua y heredada" hacia el partido demócrata de un hombre que nunca colaboró con los oligarcas, aunque incluso pudo erigirse en tirano; y que sufrió a manos de (hypo), por causa de (dia),

13

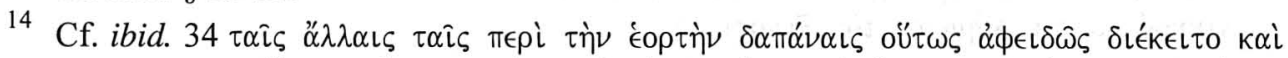

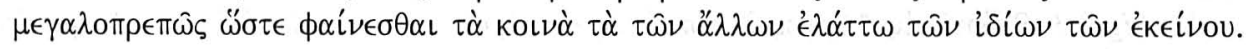

15

16

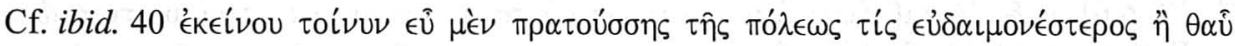

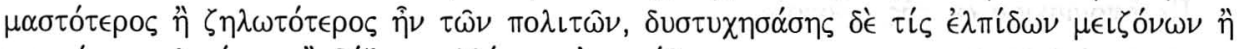

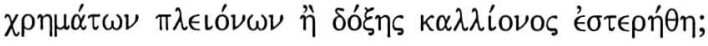


en favor de (hyper) y junto con (meta) el pueblo ${ }^{17}$. Justo lo contrario - continúa diciendo Isócrates - que Caricles, pariente del acusador y uno de los Treinta. Con esto la biografía termina y se diluye suavemente en la última parte del discurso que retorna al hijo de Alcibíades y al tema del litigio.

Pero vayamos ya a Lisias. Como se adelantó arriba, de los dos discursos citados que conserva el Corpus Lysiacum contra el hijo de Alcibíades en un proceso por no alistamiento (astrateia), el primero (XIV del Corpus) contiene, una vez más, la biografía del personaje que nos ocupa. También en este caso se ha negado la autoría de Lisias, pero no parece que haya razones de peso. Antes bien, nada se opone a que el logógrafo tomara a su cargo escribir esta acusación por encargo de un personaje perteneciente al grupo de los demócratas radicales entre los que Lisias tenía no pocas amistades. Por otra parte, la maestría que demuestra el autor del discurso para presentar el bios de Alcibíades fundiéndolo con el del hijo; y la habilidad retórica que se manifiesta en el discurso para silenciar verdades y airear falsedades, que no parecen tales, revela a las claras la mano de Lisias, el maestro supremo de la doxa y el pseudos.

Otro aspecto, relevante a mi juicio, del discurso es que su autor demuestra conocer bien el de Isócrates porque, en realidad, es una contrabiografía - si bien es más breve y está mejor integrada en la causa, que, incluso por esta razón, parece ser real y no ficticia. Pero es fácil ver que en ocasiones contesta casi literalmente a algunos de los argumentos que había esgrimido Isócrates en favor de Alcibíades; y, sobre todo, la trama profunda de la argumentación es una contrarréplica de la de Isócrates. Por todo lo cual refleja la propia estructura profunda del discurso de Isócrates, si bien Lisias funde los hechos políticos con la actitud del personaje, lo público con lo privado y lo personal con lo familiar.

En efecto, el discurso tiene todas las trazas de ser una deuterología de alguien que reconoce que en el pasado hubo rivalidad entre los padres de ambos ${ }^{18}$. Y dedica exactamente la primera mitad del mismo (24 párrafos) a justificar la acusación de deserción (en realidad alistamiento con la caballería y no con los hoplitas, que comportaba más riesgo). El discurso, por tanto, tiene todas las probabilidades de ser real y no una mera excusa. Como argumentación adicional de la actitud de Alcibíades junior, traza Lisias una semblanza del mismo en la que aparece como un libertino, como un aristócrata corrompido desde su niñez que ha pasado la adoles-

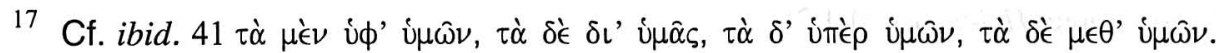

18 Cf. $\S 2$. 
cencia y la primera juventud entre orgías y actos de violencia causada y recibida. Pues bien, es aquí, precisamente, donde se inserta adecuadamente el bios del padre que ocupa 15 párrafos (del 30 al 45). En el párrafo 29 dice Lisias: «intenta humillar a otros quien debía ser el más comedido de los ciudadanos haciendo de su propia vida una defensa de los crímenes de su padre, el hijo de Alcibíades, el que persuadió a los lacedemonios para que fortificaran Decelia». La transición del hijo al padre es, por tanto, muy suave y natural. Lisias elimina toda alusión al tema de los Hermes y de los Misterios y comienza, in medias res, con los crímenes de Alcibíades contra la polis: el tema de Decelia, la expedición a las islas para que hicieran defección, su alianza, en fin, con los lacedemonios contra Atenas: «luchó más veces con el enemigo contra su patria que contra el enemigo por su patria» ${ }^{19}$ - frase que le exime de enumerar hechos más concretos y que resulta retóricamente más eficaz.

$\mathrm{Y}$, unido a esta enumeración de sus traiciones, y en una pirueta retórica típicamente lisíaca, hay un largo pasaje de meiosis (minutio o amplificatio inversa) donde lo que pretende el orador es empequeñecer al personaje y eliminar cualquier impresión de su unión con la grandeza de la polis: Alcibíades no fue tan importante como para ser responsable de todo lo que le ocurrió a la ciudad, ya sea bueno o malo, como afirman sus partidarios. Cierto que cuando estaba exilado perjudicó a Atenas, pero ni siquiera eso tiene mérito: es fácil para cualquiera señalar los puntos débiles de su propia ciudad. $\mathrm{Y}$, una vez que regresó, no fue capaz de ganar ninguna batalla ni granjearse el favor ni los dineros - del Gran Rey; en fin, tuvo la cobardía de exiliarse a Tracia en vez de sufrir junto con la polis. Y, para concluir, entregó las naves a Lisandro junto con Adimanto. Esto último, que se refiere a la batalla de Egós Potamós, es abiertamente falso. Precisamente fue uno de los momentos en que Alcibíades intentó ayudar a Atenas aconsejando a los generales a que rectificaran la posición errónea de la flota ateniense en el Helesponto, como sabemos por Jenofonte ${ }^{20}$. En los hechos anteriores, más que mentiras lo que hay es una clara suppressio veri: silencia la brillante victoria que Alcibíades logró en Cícico y no señala que el culpable de la derrota de Notion, y su consiguiente exilio a Tracia, fue Antíoco, su segundo en el mando ${ }^{21}$. Y que si no consiguió dinero del Rey, no fue por culpa suya.

Una vez torcidos los hechos y manipulados para denigrar el carácter de Alcibíades, Lisias - lo mismo que Isócrates - se vuelve ahora a su familia. Pero a

19 Cf. $\S 30$.

20 Cf. Jenofonte, Helénicas, II 1.25.

21 Cf. ibid. I 5.11. 
partir de este mismo momento Lisias hace algo sorprendente y retóricamente brillante: funde y confunde habilidosamente la biografía de ambos Alcibíades entre sí y con la de toda la familia. A partir de ahora (\$ 41-43) todos los verbos están en plural y ya no se distingue entre ninguno de los miembros de la familia, ni entre delitos públicos o privados: «no es el caso que haya que perdonarlos porque en 1o público son malos y en lo privado honestos», sentencia el orador. Con ello Lisias pretende demostrar justamente lo contrario que Isócrates, y con el mismo argumento: que Alcibíades junior, el acusado en el proceso, es un enemigo hereditario de la ciudad: sus bisabuelos fueron condenados al ostracismo; su padre fue condenado a muerte; "la mayoría" se han prostituido; "otros" se han acostado con sus hermanas; "otros" han mutilado los Hermes y se han mofado de los Misterios; en fin, "todos ellos" se avergüenzan de las buenas acciones y se enorgullecen de las malas. El punto álgido de la meiosis se encuentra en la conclusión de esta biografía, que comenzó con el hijo, continuó con el padre y ha terminado con toda la familia - es decir, siguiendo un orden cronológico inverso al que es habitual en la biografía. Lo mismo que Alcibíades padre no tuvo la influencia que dicen sus amigos, el hijo no puede beneficiar al pueblo siendo bueno ni perjudicarlo siendo malo. Es decir, es un peso muerto sobre la tierra. Es decir, carece de arete. Esta es la contraconclusión que deduce Lisias pensando, sin duda alguna, en el discurso de Isócrates. Si éste, como antes señalé, resalta la arete plena de Alcibíades, la posesión del valor, la moderación, la justicia y la inteligencia - y ello por herencia de sus antepasados - Lisias ha venido subrayando de una forma tácita justamente lo contrario: los Alcibíades son cobardes (carecen de andreia), son libertinos (carecen de sophrosyne), son injustos (carecen de dikaiosyne) y no tienen ni siquiera inteligencia para el mal. Es la kakia en su sentido más amplio y más helénico: la maldad inútil de Margites.

Voy a terminar tratando de derivar (más bien resumir y repetir) algunas conclusiones a partir de las consideraciones que acabo de exponer sobre el bios de Alcibíades en los rétores. La mayoría, desde luego, desarrollan ideas, o insisten en aspectos de la biografía que se han expresado anteriormente. Lo primero, quizá, que se deduce es la confirmación de que en el siglo $\mathrm{V}$ existía ya la biografía. Desde luego no parece lógico que se hubiera independizado como género, porque no parece que existieran las condiciones para ello, pero hay bioi como partes - a veces sustanciales - de otros géneros: para empezar, de la Historia, como se ha dicho tantas veces. Pero quisiera insistir que también existen la biografía y la autobiografía integradas en el género de la Oratoria como un elemento más de la demostración, ya sea bajo la forma de epainos o como diabole según los casos - y no sólo en los procesos de dokimasiai ni en el género epidíctico. A mi entender es, sobre todo, en el 
genos dikanikon donde tiene mayor presencia e importancia. También es posible, desde luego, aunque difícil de demostrar, que ya se hubiera independizado sin desprenderse del propio marco de un discurso: en este caso lo que tendríamos son biografias encubiertas so capa de procesos ficticios. Hay quienes piensan, por ejemplo que los tres discursos aquí aducidos son panfletos políticos ${ }^{22}$. En todo caso, y esto parece importante, en mi opinión es precisamente este marco retórico el que hace que la biografía tenga desde el principio el hamartema original de su carencia (o su no exigencia) de objetividad; y la orientación eminentemente ética que tendrá cuando cobre independencia. Un bios, independiente o no, es siempre un paradigma ético que se propone como algo que se debe seguir o evitar. Naturalmente también será, más tarde y por influencia del género histórico y la filosofía, un exemplum sobre la actuación caprichosa del azar, o sobre la providencia en una consideración más religiosa, cristiana o no. Pero en definitiva será una lección sobre el rhythmos que gobierna la condición humana, como diría Arquíloco. No me parece necesario repetir que la biografía como crónica detallada de los hechos y dichos de un individuo es una creación moderna.

Finalmente, si la biografía sirve para vehicular las ideas sobre el comportamiento moral individual, con mayor motivo se convierte desde sus inicios en un instrumento de ideología política. Se puede ver - y eso es lo que he intentado aquí - que en el caso de Alcibíades su biografía es una mera excusa para justificar las acciones y la actitud política de este personaje - y sobre todo de su grupo de partidarios; o para lo contrario, en el caso de sus adversarios políticos. Lo mismo sucede con la de Terámenes o la del propio Lisias en los discursos XII y XIII del Corpus Lysiacum. El mayor o menor éxito persuasivo consistirá, precisamente, en ocultar los mecanismos de manipulación. Y en este terreno todos sabemos que Lisias fue el más grande de los maestros. 
(Página deixada propositadamente em branco) 


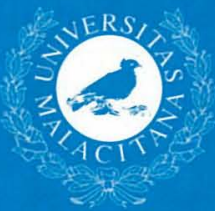

